\title{
Multidisciplinary peer-led Sexual and Reproductive Health education programme in France, a prospective controlled-study
}

Anaïs Nuttall ( $\square$ anais.nuttall@gmail.com )

Aix-Marseille Universite https://orcid.org/0000-0003-3288-0279

Julien Mancini

Assistance Publique - Hôpitaux de Marseille: Assistance Publique Hopitaux de Marseille

Camille Lizin

Nice Sophia Antipolis University: Universite de Nice Sophia Antipolis

Sabrina Hamzaoui

Aix-Marseille Université: Aix-Marseille Universite

Sophie Mariotti

Reseau Périnatalité Méditerranée

Heloise Louesdon

Réseeeau Périnatalité Méditerranée

Sophie Tardieu

Assistance Publique - Hôpitaux de Marseille: Assistance Publique Hopitaux de Marseille

Jean-Michel Viton

Assistance Publique - Hôpitaux de Marseille: Assistance Publique Hopitaux de Marseille

Jerome Delotte

CHU Nice: Centre Hospitalier Universitaire de Nice

Florence Bretelle

Assistance Publique - Hôpitaux de Marseille: Assistance Publique Hopitaux de Marseille

\section{Research article}

Keywords: Peer-led sexual education, sexual health, teenagers, healthcare students

Posted Date: May 19th, 2021

DOI: https://doi.org/10.21203/rs.3.rs-537238/v1

License: (c) (i) This work is licensed under a Creative Commons Attribution 4.0 International License.

Read Full License 


\section{Abstract}

Background: Sexual education is an international priority to promote sexual and reproductive health $(\mathrm{SRH})$ and to reduce risky sexual behaviour. Experts recommend holistic and comprehensive SRH peer-led education.

In 2018, the French government launched a new public health peer-led prevention programme called "Service Sanitaire" (SeSa), consisting of health education provided by healthcare students (peer educators) to teenagers. During the first year of the programme and for the first time in France, the impact of the programme was prospectively evaluated to examine whether the programme improved the SRH knowledge of healthcare students and teenagers. Risk perception and risky sexual behaviour among these populations were also evaluated.

Method: A prospective multicentre controlled study was conducted from November 2018 to May 2019. $\mathrm{SRH}$ knowledge was compared before and after the SeSa programme, and the evolution of this knowledge was compared, with linear regression, between healthcare students benefiting from the SRH SeSa programme and those who were part of another programme. The same analyses of knowledge were performed for teenagers who received the SeSa SRH interventions compared to teenagers who had no specific SRH education programme. Risk perception and risky behaviour were studied before and after the programme among healthcare students and among teenagers.

Results: More than $70 \%$ of the targeted population participated in the study, with 747 healthcare students and 292 teenagers. SRH peer educators increased their knowledge score significantly more than other peer educators (a difference of 2.1 points/30 [95\% Cl $1.4-2.9]$ (p[between group] < 0.001)). Teenagers receiving the $\mathrm{SeSa}$ intervention also had a greater increase in their knowledge score than the other teenagers $(+5.2 / 30$ [95\% $\mathrm{Cl} 3.2-7.4]$ p [between group] $<0.001)$. There was no evidence of change in sexual risk behaviours for the healthcare student population.

Conclusion: The "Service Sanitaire" programme significantly improved the sexual and reproductive health knowledge of peer-educator healthcare students and teenagers compared to a classic education programme. Longer and/or qualitative studies are needed to evaluate changes in sexual behaviour as well as positive aspects of sexuality.

\section{Introduction}

Adolescents and young adults, people who are undergoing biological and psychological change, are known to be more vulnerable and at higher risk regarding sexual and reproductive health (SRH)(1). In 2018, in France, 224300 unwanted pregnancies resulted in abortions and the highest rate was among 20to 24-year-old women(2); moreover, reproductive tract infections (RTIs) among the young population (1525 years old), such as Chlamydia trachomatis, increased by $37 \%(3)$. Holistic sexual and reproductive health (SRH) education could be one legitimate answer for such a global public health issue(4-6). According to the literature, school-based SRH intervention is effective in changing SRH knowledge, 
attitudes and skills in the young population $(1,7)$. WHO defines SRH as "A state of physical, emotional, mental and social well-being in relation to sexuality; it is not merely the absence of disease, dysfunction or infirmity. SRH requires a positive and respectful approach to sexuality and sexual relationships, as well as the possibility of having pleasurable and safe sexual experiences, free of coercion, discrimination and violence"(8).

Since 2001, three sessions of sexual and reproductive health (SRH) education per year have been planned by French law for children from 3 to 17 years old(9) despite the very poor adherence by public institutions(10). These sessions are organized and planned by institution directors and are led by school nurses, teachers or external nongovernmental organizations(10). For $99 \%$ of French secondary schools (age 11 to 15), biology classes include SRH education as part of the human reproduction curriculum, and sessions are mostly performed by school nurses or biology teachers for teenagers at ages 13 and 14(10). In contrast to this approach, peer-led health education in general and peer-led sexual health education in particular, education by "members of similar age or status groups" $(11)$, is recommended(12,13) and has demonstrated to be efficient in increasing knowledge of sexual and reproductive health among teenagers and young adults by several studies and Cochrane reviews (14-17). The advantage put forward is that this information is more appealing and credible when provided by peers. Thus, peer-led sexual education reaches two populations targeted by SRH (the educators trained by sexual education experts and the second population whom the educators teach) and increases their SRH knowledge with a single programme(18).

In 2018, the French government launched a new public health peer-led prevention programme called "Service Sanitaire" (SeSa), which is mandatory for every healthcare student to obtain a degree. Its aim is to teach healthcare students of all branches (medical doctors, physiotherapists, dentists, pharmacists, and midwives) priority topics (nutrition, addiction, dental hygiene and sexual health) and for these students to transfer their knowledge to secondary or primary school students(19). Healthcare students constitute a suited peer-educator population; their shared student status and the small difference in age (5 years) with secondary school students gives these peer educators both trust and legitimacy with teenagers. Moreover, healthcare students could benefit from these interventions given their need for SRH knowledge improvement according to French and international recommendations $(12,13,20)$. In addition, the healthcare students tend to have difficulties addressing sexual subjects with patients because of a lack of knowledge(21), whereas the peer-teaching method in the medical student population has been shown efficient in increasing SRH knowledge(22).

Although peer-led SRH education has been studied, there is no study, to our knowledge, evaluating multidisciplinary healthcare students as peer educators in SRH education.

During the first year of the programme and for the first time in France, we prospectively evaluated the impact of the SeSa programme on SRH knowledge among healthcare students and teenagers participating in the SRH part of the programme compared with students benefiting from classic national health education. We also evaluated risk perception and risky sexual behaviour among these populations. 


\section{Methods}

\section{Study Design:}

The Mediterranean Perinatology Network led this multicentric observational prospective controlled study from November 2018 to June 2019 in Aix-Marseille and Nice Sophia-Antipolis Universities. Two populations were studied: the first population included healthcare students (peer-educators) participating in the SRH part of the SeSa programme (SRH peer-educators) who were compared to healthcare students participating in other modules (nutrition, addiction, and dental hygiene) (other peer-educators), and the second population included secondary school students (teenagers) benefiting from the SeSa SRH programme (SeSa-intervention teenagers) who were compared to secondary school students receiving the classic national education programme (no-intervention teenagers). Although the ages would not be the same, both populations are students and can be considered peers given the small age difference between the groups and their shared student status. Levels of knowledge, risk perception and risky behaviour were studied before and after the SeSa programme among those populations (Figure 1).

The programme for healthcare students included 20 hours of global health prevention courses, 31 hours of specific prevention (addiction, dental hygiene, nutrition and sexual education) and one to four field interventions during which the healthcare students communicated their knowledge to the teenagers. Gynaecologists, SRH education experts, and governmental and nongovernmental organizations specializing in reproductive health and health education led the $\mathrm{SRH}$-specific programme during the 31 hours and covered RTIs and HIV/AIDS information and prevention, contraception, abortion procedures, rights and laws, sexual and gender minority awareness and legal aspects as well as matters of respect and consent. Five healthcare students per group, one from each health branch (dentist, medical doctor, midwife, pharmacist and physiotherapist), led the field interventions. The logistical aspects and duration of the interventions were decided and organized by the schools participating in the SeSa programme. Interventions lasted for one to four hours for one class on one day.

The classic French national secondary school curriculum includes reproductive health during the penultimate year, and school attendance is mandatory until 16 years of age. These two grades represented the most relevant groups of students to study.

\section{Procedure:}

We recruited all students of all healthcare branches participating in the SeSa programme as planned by law at Aix-Marseille and Nice Sophia Antipolis Universities as follows: the first year of studies for the dental care and midwifery schools, the second year for pharmacy and physiotherapy schools and the third year for the school of medicine. Healthcare students were randomly assigned to one module of the programme, except for midwives in Nice who were assigned to the SRH module as an organizational matter. Each healthcare student participating in the SeSa programme was invited to answer a questionnaire in November 2018 before participating in any course. At the end of the entire programme, in 
May 2019, the same questionnaire was again provided. Information on age, gender and type of study (dentistry, medicine, midwifery, physiotherapy, and pharmacy) was collected.

For teenagers, we recruited voluntary secondary schools in Marseille and selected the penultimate and last year of secondary school (13-15 years old). Teenagers were invited to complete a questionnaire before the interventions in February 2019. The same questionnaire was given three months after the end of the programme. Schools not participating in the SeSa programme received the first questionnaire in February or March 2019 and the postintervention questionnaires in May or June 2019 to respect a 3month delay between the administration of the two. Information on age, class, school and gender were collected.

For reasons related to participation, organization and anonymity, the data collected in this study were not paired. Anonymity numbers, first planned in the study, were not possible given the number of participants and the lack of adherence expected if total anonymity was not ensured to both teenagers and healthcare students. Since students were part of a specific programme, we assumed that they would not change. The investigators distributed the questionnaires. Neither the schoolteachers nor the university professors had access to the documents.

\section{Participants:}

To participate in the study, peer educators (SRH and others) had to be on 2018 promotion (which meant part of the SeSa programme), speak French and be over eighteen years old. For teenagers, inclusion was possible if parents or legal guardians had consented to the study, and access to the postintervention questionnaire was not possible if the pretest questionnaire had not been completed (absent and/or no legal authorization). The distribution of participant variables is presented in Figure 1.

\section{Outcome Measures:}

The primary outcome, knowledge acquisition, was measured with 30 "true or false" questions (TFs) for healthcare students (also called peer educators) and teenagers as well as 30 additional multiple-choice questions (MCQs) for health students. The number of participants required was 1000 participants and was determined to have $80 \%$ statistical power and a bilateral significance of $5 \%$, assuming a difference of $12 \%$ between the two groups in the postintervention score. The questions assessed knowledge of contraception use, reproductive Tract Infections (RTIs), French SRH laws (access to abortion, free contraception, laws against homophobia, and access to pornography) and reproductive biology.

For the secondary outcome, risk perception was measured using a Likert scale(23) from 0 to 5. Participants had to decide about the level of risk of a situation, between not risky (0) and very risky (5). Eleven situations assessed the perception of pregnancy and the transmission risk of RTIs at first intercourse, with or without a barrier protection method (condom). Information on behaviour was collected using an adapted version of the Centers for Disease Control and Prevention's Youth Risk Behavior Survey (24). Participants were asked to record their age at first intercourse, lifetime number of 
partners and the number of partners in the last three months, the contraceptive method used, if needed, and the use of alcohol or drugs, and condoms during last intercourse. The participants were also asked whether they had "risky intercourse" (unprotected sex without knowing the RTI status of the partner) during the last two months.

\section{Analysis:}

The quantitative data are reported as the mean \pm standard deviation or as the median [minimummaximum] and were compared using Student's t-test or the Mann-Whitney tests. The categorical data are reported as the absolute count (percentage) and were compared using the $\chi^{2}$ test. Spearman's rank correlation coefficient $(\rho)$ was used to study the relationship between continuous and/or ordinal variables. The $p$ for interaction between the timing of the questionnaire (pre-or postintervention) and the intervention (exposure or not to the SRH SeSa programme) was computed in a linear regression model to test the differential changes in quantitative outcomes among healthcare students and teenagers (p[between group]). All tests were two-sided. Differences were considered significant when the $p$ value was less than 0.05. Statistical analyses were performed using IBM SPSS Statistics 20.0 (IBM Corp., Armonk, NY, USA).

\section{Ethical considerations:}

Healthcare students, secondary school students and their legal guardians gave their consent to participate in the study. The study received the approval of the French National Committee for Person's Protection (CPP) (national number: 2018-A03066-49) and the National Committee for Data Protection and Liberties (national number: 2212148v0).

\section{Results}

\section{Samples:}

Out of 1049 healthcare students (peer educators) participating in the programme, 747 questionnaires were collected pretest (71\% participation rate), and 948 were collected posttest ( $90 \%$ participation rate) (Figure 1). There were 277 SRH peer-educators with 206 questionnaires collected pretest $(74 \%$ participation rate) and 254 responses collected posttest ( $92 \%$ participation rate). The responses of these peer educators were compared to those of 772 other peer-educators, with 541 questionnaires at pretest (70\% participation rate) and 694 at posttest (90\% participation rate). Regarding the teenagers, out of 225 participants recruited in the SeSa intervention arm, 71 participants could not provide parental authorization, 154 questionnaires were collected before the intervention (68\% participation rate) and 136 after the intervention (answer rate 60\%). In the no-intervention arm, 176 teenagers were recruited, 38 did not have parental authorization, and 138 questionnaires were collected pre- and posttest, respectively (78\% participation rate). 
As shown in Table 1, the distribution of gender, age, and age at first intercourse were similar between the SRH peer-educators and other peer-educators at baseline. The health branch representation was different between the SRH peer-educators and the other peer-educators, which was due to a higher number of midwives in the SRH peer-educator group. This result is explained by the fact that in Nice city, midwives were assigned to the SRH study area for organizational reasons.

For teenagers, age was higher in the group benefiting from the SRH SeSa programme than in the other group (14.2 \pm 0.7 y.o. vs $13.4 \pm 0.5$ y.o. $p<0.001$ ), but the gender distribution was similar between the two groups $(p=0.9)$ (Table 1). Even if the questionnaires were not paired, there was no evidence of betweenpopulation differences in the pre- and posttest scores for each city; neither the distribution by gender $(\mathrm{p}=$ 0.8 for Marseille and $p=0.7$ for Nice) nor intervention arm differed $(p=0.9$ for Marseille and $p=0.6)$.

\section{Primary outcome:}

Peer-educators:

There was a significant increase in the mean score of SRH peer-educators between November 2018 and May 2019. The results show an increase of 2.0 points [95\% $\mathrm{Cl} 1.6-2.5]$ out of 30 in the SRH peereducator group vs a decrease of -0.1 points [ $95 \% \mathrm{Cl}-0.5-0.3$ ] out of 30 in the other peer-educator group for the true-false score. The difference in score between the two groups was significant, with a greater increase for SRH peer-educators than for other peer-educators (difference of 2.1 points [ $95 \% \mathrm{Cl} 1.4-2.9$ ] (p[between group] $<0.001)$ ). The results were similar for the multiple choice question score, with an increase of 1.6 points out of 30 [0.9 - 2.2] in the SRH peer-educator group vs a decrease of 1.1 points out of 30 [-1.6 - -0.7] in the other peer-educator group between November 2018 and May 2019. The difference in score was also significant, with a greater score increase for the SRH peer-educator group than for the other peer-educator group (difference of 2.7 [95\% Cl 1.8 - 3.6] (p[between-group] < 0.001)) (Table 2).

The lifetime number of sexual partners was negatively correlated with worse pretest and posttest scores for the multiple-choice questions $(\rho=-0.1 p=0.12$ before the intervention and $\rho=-0.1 p=0.009$ after the intervention). The relevant results are presented above, and the results of each question are presented in appendix 1 for true-false questions and in appendix 2 for multiple-choice questions. A higher increase in score was found for the question about the need for a pelvic examination before beginning to use hormonal contraceptives in SRH peer-educators compared to other peer-educators: $39 \%(n=80)$ correct answers before the SeSa programme vs $79 \%(n=200)$ after SeSa in the SRH peer-educator group compared to $47 \%(n=255)$ vs $48 \%(n=336)$ in the other peer-educator group ( $p[$ between group] $<0.001)$ (see appendix 1). Similar results were found for questions about female virginity, legal access to abortion for minors, and emergency contraception. Scores for specific items, such as the epidemiology of abortion, technical aspects of hormonal contraception prescription and use, were low pretest, but the results showed a great posttest increase in the SRH peer-educator group (mean score 0.40/1 \pm 0.22 before the SeSa programme vs $0.48 \pm 0.26$ after $p$ [within-group] $<0.001$ for the abortion question, and a mean score of $0.39 / 1 \pm 0.47$ before SeSa vs $0.48 \pm 0.25$ after SeSa p[within-score] $<0.001$ for the contraception question). 


\section{Teenagers:}

The same result was found in the teenage population, with a higher increase in the SeSa programme intervention group $(+6.7$ points out of 30 [5.2 - 8.2] $(p<0.001)$ vs $+1.4 / 30[-0.1-2.9](p=0.006))($ Table $2)$. The difference in scores was significant $(p<0.001)$. Age was correlated with a better pretest score $(\rho=$ $0.2 p<0.001$ ). Girls received higher scores than boys in the postintervention test (girls $21.3 / 30-$ boys $18.3 / 30)$, and the mean change in score tended to be higher for girls (+2.3 points between boys and girls [CI 95\% -0.6 - 5.2] p=0.1). Knowledge acquisition was significantly better in the SeSa programme intervention group than in the no intervention group for questions related to the technical use of hormonal contraception ( $\mathrm{p}[$ between group]=0.01) and female and male pleasure (p[between group]=0.01) (appendix 3). Higher rates of correct answers were found at posttest in the SeSa-intervention teenager group but the between-group comparison was not significant for the technical aspects of condom use $(83 \%(n=127)$ correct answers at pretest vs $85 \%(n=115)$ at post-test in the SeSa-intervention group compared to $78 \%$ $(n=108)$ vs $72 \%(n=99)$ in the no-intervention group, $p[$ between group] $=0.24)$. The same results were found for knowledge of abortion laws (36\% ( $n=55)$ correct answers before SeSa vs 72\% ( $n=98)$ after SeSa in the SeSa-intervention group compared with $15 \%(n=20)$ vs $34 \%(n=47)$ in the no-intervention group, $p$ [between group] = 0.29) and questions about virginity $(16 \%(n=25)$ correct answers before SeSa vs $43 \%$ $(n=59)$ after SeSa in the SeSa-intervention group compared to $7 \%(n=10)$ vs $16 \%(n=22)$ in the nointervention group, $\mathrm{p}[$ between group] $=0.09$ ). Despite a significant increase in the percentage of correct answers, some rates of correct answers remained low after the SeSa programme in the SeSa-intervention group for specific items, such as the role of boys in contraceptive use $(36 \%(n=55)$ before SeSa vs $48 \%$ $(n=65)$ after (p[within group]= 0.04)) and knowledge of the erogenous zones of boys $(12 \%(n=19)$ vs $41 \%$ $(n=56)$, p[within group] $<0.001)$. The results by question are presented in appendix 3.

\section{Secondary outcomes:}

\section{Peer-educators:}

Risk perception was significantly higher after the SeSa programme for both peer-educator groups, with a higher but not significant increase in the SRH peer-educator group (Table 2, p[between group]=0.3]. The risk perception of each situation is presented in appendix 4. The results highlight a higher increase in the score for the risk perception of pregnancy after first intercourse (from 3.7/5 \pm 1.4 to $4.21 / 5 \pm 1.2$ for $\mathrm{SRH}$ peer educators vs from $2.72 \pm 1.4$ to $3.01 \pm 1.3$ for other peer educators) and for after condom rupture in the SRH peer-educator group (from 4.11/5 to 4.40/5 ( $p=0.002)$ vs 4.03 to $4.02(p=0.89)$ for the other peereducator group) (see appendix 4, p[between group]=0.02 for both questions). Ninety per cent of the healthcare students had already had sexual relations, and the median age of first intercourse was 17 years of age. Among respondents, $58.2 \%(n=543)$ had had 3 or fewer sexual partners in their lifetime, and $63.5 \%(n=590)$ had only one partner during the last three months. When pregnancy was not desired, the most commonly used contraceptive method at first intercourse was condoms (59\%), followed by condoms combined with oral contraception (14\%) and oral contraception (7\%). Only $4 \%$ of respondents did not use any contraception, $1 \%$ used the withdrawal technique and $2 \%$ had other contraceptive 
methods (an intrauterine device, implant, or other). There were no significant changes in risky behaviours among the peer-educator population. Our study showed that after 3 months of a 4-month programme, there was no evidence of change in alcohol or drug use before last intercourse ( $20 \%$ before vs $13.2 \%$ after the SeSa programme $\mathrm{p}=0.61)$, condom use during last intercourse $(40.8 \%$ vs $40.4 \% p=0.93)$ and last intercourse at risk $(12.0 \%$ vs $14.0 \% \mathrm{p}=0.55)$ for $\mathrm{SRH}$ peer educators in comparison to before the programme (Table 3$)$.

\section{Teenagers:}

Risk perception tended to increase in the SeSa-intervention group at posttest without reaching significance $(3.07 / 5 \pm 0.71$ before the SeSa programme and 3.17/5 \pm 0.74 after the SeSa programme $p=0.21$ ), whereas it tended to decrease in the no-intervention group ( $3.03 \pm 0.87$ vs $2.92 \pm 0.92 p=0.30$ ).

Given the small number of sexually active teenagers at baseline, the change in risky behaviour was not interpretable ( $n=6$ for the SeSa-intervention group and $n=3$ for the no-intervention group).

\section{Discussion}

\section{Main findings:}

The multidisciplinary health prevention programme "Service Sanitaire" significantly increased the sexual and reproductive health knowledge of healthcare students as peer educators and teenagers more than a classic education programme. As with other peer-led programmes, education by healthcare students is popular among teenagers given their shared student status and the more informal exchanges they can have compared to those they have with their teachers. For healthcare students, a multidisciplinary approach led to more communication and learning from each other beyond the usual boundaries, and creating a programme together helped them to be invested in their topics and gave them responsibilities regarding legitimate needs. The SeSa programme also significantly improved the sexual and reproductive risk perceptions of the healthcare students. There was no evidence of impact on the risk behaviours three months after the acquisition of knowledge in the four studied groups (SRH peer-educators, other peereducators, SeSa-intervention teenagers, and no-intervention teenagers). The delay between the acquisition and retention of knowledge and sexual behaviour was a limitation. A period of 4 months, as in other studies $(25,26)$, seems to be too short to evaluate the impact of such a programme.

An unexpected finding was the reduced knowledge score at posttest compared to pretest among health care students in other programmes. This result might come from a lack of interest for the subject matter and for the study being conducted at the end of the year considering the time they spent on other prevention items.

It should be pointed out that this study was the first to evaluate the new French national programme. To our knowledge, SeSa is the only programme combining peer-led SRH education and a multidisciplinary approach at a national level. We were able to ensure the multidisciplinary approach in the evaluation, as 
we included and studied every branch of healthcare studies. The results were similar to those reported by other programmes $(18,25,27)$ and in programme reviews $(16,28,29)$. Moreover, the Nice and Marseille scores and improvement rates were similar. Our population had the same age at first intercourse and the same type of contraceptive use as the French national population (30). The study benefited from a high response rate, and we were able to enrol most of the 2018 - 2019 healthcare student classes participating in the SeSa programme. This study included and represents more than 700 peer-educators and over 300 teenagers.

The main limitation to the study is inherent to the study design. It is difficult to evaluate, in a declarative mode, sexuality among teenagers. The age at first intercourse in France occurs at approximately 17 years old (30), and our population was 14 years old; thus, teenagers have not yet become sexually active. Moreover, the questionnaires were distributed inside the classrooms for both populations. Even if we tried to reduce this bias by avoiding involving teachers in the process, it is hard to neglect the school's impact on the responses. Another limitation was the need for total anonymity to collect sensitive data, which compelled us to not to pair the questionnaires. As discussed and given the distribution of our population in both groups at pretest and posttest, it is more likely that our population remains representative for both tests.

The SeSa programme is an interesting programme that meets the International and National Guidelines on Sexual and Reproductive Health Education $(10,12,20)$. Only in the SUD region (south of France) and all modules considered (SRH, nutrition, dental hygiene and addiction) did SeSa conduct 6000 class interventions, which represents more than 150000 pupils reached by this national governmentally funded programme. With the same programme and at a low cost, two populations were targeted for sexual and reproductive health issues $(5,10)$. Both populations will be able to use the knowledge acquired from the programme in their future lives (for teenagers) and in their future practices (for healthcare students)(31). This study also provides ways to improve the programme. The increases in scores for items such as knowledge of abortion procedures and the epidemiology of abortion, specific aspects of hormonal contraception prescriptions and the use of these methods indicates the effectiveness of communicating information on these topics and the necessity to extend such a programme to reach a broader population. In contrast, the fact that scores on questions about the roles of boys in contraception and knowledge of the erogenous zones of boys remained low after the SeSa programme in the teenage population could lead to the improvement of this part of the programme's curriculum. The results also show that teenage girls tend to learn better from the programme. This outcome has been pointed out in other studies $(14,18)$ and could suggest that more attention has to be paid to the teaching of boys to close this gap.

However, the SeSa programme does not seem to reduce risky behaviours. Although the increase in knowledge is a serious part of the process, the transformation of risky behaviour is a complex mechanism in which school is not the only component(26). First, school is currently not the only and major source of information for teenagers and young adults, and social media represents an important part of it(1). In addition, with such a short period between knowledge acquisition and the assessment of 
any changes in risky behaviour, the conclusions can be misleading. This study demonstrates the effectiveness of peer-led programmes in increasing sexual and reproductive health knowledge. It could be interesting to use this type of programme combined with social media support for the young population, which has shown efficient in changing sexual health behaviour(32,33). An important point to make is that sexual and reproductive health is a large and global issue that is difficult to assess with evidence-based medicine. The results presented in the study evaluated a small aspect of SRH. Satisfying sexual relationships, positive sexual self-perception, partner empathy and positive preventive behaviours are many aspects composing holistic sexuality education that was taught during the SeSa programme and are known to be efficient and welcome among the targeted population(34) but are difficult to translate into factual indicators(26). These factors tend to be included in sexual health programmes and are part of the sustainable development global recommendation(5). Further studies with a longer timeframe and/or with a qualitative approach could provide a better analysis of these factors.

\section{Conclusion}

Our study shows that the "Service Sanitaire", a French national health prevention programme, increases sexual and reproductive health knowledge among healthcare students and primary school pupils. Further programmes and studies should be developed to decrease sexually risky behaviours in this population with a long-term timeframe.

\section{Declarations}

\section{Authors' contribution:}

Conceptualization, supervision and coordination was performed by Pr Florence BRETELLE, head of The Mediterranean Perinatology Network (www.reseauperinatmed.fr). Dr Anaïs NUTTALL wrote the protocol, collected data, analyzed the results and wrote the manuscript. Pr Julien MANCINI assessed statistics and methodological aspects. Secondary schools were contacted and coordinated by Sophie MARIOTTI and healthcare students by Sophie MARIOTTI in Marseille and Helö̈se LOUESDON in Nice. Camille LIZIN and Sabrina HAMZAOUI contributed to collect data among healthcare students. Sophie TARDIEU participated to the study design and methodological aspects. Pr Jerome DELOTTE supervised and supported the study in Nice. Pr Jean-Michel VITON, as Marseille Medicine School's director, coordinated the Service Sanitaire and supported the study. All authors read and approved the final manuscript.

Conflict of interest: The authors declare that they have no conflict of interest.

Ethical approval: Healthcare students, secondary school students and their legal representative gave their consent to participate in the study. It received the approval of the French National Committee for Person's Protection (CPP) (national number: 2018-A03066-49) and the National Committee for Data Protection and Liberties (national number: 2212148v0).

Availability of data and materials: Datas are available by simple request to the first author. 


\section{References}

1. Garzón-Orjuela N, Samacá-Samacá D, Moreno-Chaparro J, Ballesteros-Cabrera MDP, EslavaSchmalbach J. Effectiveness of Sex Education Interventions in Adolescents: An Overview. Compr Child Adolesc Nurs. 2020 12;1-34.

2. Vilain A. 224300 IVG en France en 2018. Etudes Résultats DREES. 2019;(1125).

3. Viriot D, Ndeikoundam Ngangro N, Lucas E, Dupin N, De Barbeyrac B, Bertolotti A, et al. Dépistage des IST bactériennes dans le secteur privé en France, 2006-2018. Bull Epidémiol Hebd. 2019;(31-32):63441 ;

4. Adewole I, Gavira A. Sexual and reproductive health and rights for all: an urgent need to change the narrative. The Lancet. 2018;391(10140):2585-7.

5. United Nations. Transforming our world: the 2030 Agenda for Sustainable Development. Div Sustain Dev Goals N Y NY USA. 2015;

6. Kalmuss D. Nonvolitional sex and sexual health. Arch Sex Behav. 2004;33(3):197-209.

7. Denford S, Abraham C, Campbell R, Busse H. A comprehensive review of reviews of school-based interventions to improve sexual-health. Health Psychol Rev. 2017;11(1):33-52.

8. WHO. WHO Standards for Sexuality Education in Europe - Amsterdam University of Applied Sciences. 2010.

9. Loi n 2001-588 du 4 juillet 2001 relative à l'interruption volontaire de grossesse et à la contraception. 2001-588, 2001.

10. Haut Conseil à l'Egalité femme-Homme. Rapport du Haut Conseil à l'égalité femme-homme relatif à l'éducation à la sexualité. 2016. Report No.: 2016-06-13-SAN-021.

11. Milburn K. A critical review of peer education with young people with special reference to sexual health. Health Educ Res. 1995;10(4):407-20.

12. Haut Conseil de Santé Publique. Santé sexuelle et reproductive. Paris: Haut Conseil de la Santé Publique; 2016.

13. UNESCO. International technical guidance on sexuality education: an evidence-informed approach. 2nd rev. ed. 2018.

14. Bretelle F, Shojai R, Brunet J, Tardieu S, Manca MC, Durant J, et al. Medical students as sexual health peer educators: who benefits more? BMC Med Educ. 2014;14:162.

15. Kim CR, Free C. Recent Evaluations of the Peer-Led Approach in Adolescent Sexual Health Education: A Systematic Review. Perspect Sex Reprod Health. 2008;40(3):144-51.

16. Lopez LM, Bernholc A, Chen M, Tolley EE. School-based interventions for improving contraceptive use in adolescents. Cochrane Fertility Regulation Group, editor. Cochrane Database Syst Rev. 2016;

17. Wong T, Pharr JR, Bungum T, Coughenour C, Lough NL. Effects of Peer Sexual Health Education on College Campuses: A Systematic Review. Health Promot Pract. 2018 24;152483991879463. 
18. Stephenson J, Strange V, Forrest S, Oakley A, Copas A, Allen E, et al. Pupil-led sex education in England (RIPPLE study): cluster-randomised intervention trial. The Lancet. 2004;364(9431):338-46.

19. Gouvernement. Décret $n^{\circ}$ 2018-472 du 12 juin 2018 relatif au service sanitaire des étudiants en santé. 2018-472 Jun, 2018.

20. Ministère de la Santé. Stratégie Nationale de Santé Sexuelle - Agenda 2017 - 2030. 2017.

21. Lm O, Lcf S, Jr FF. Sexual health education among undergraduate students of medicine. Transl Androl Urol. 2020;9(2):510-5.

22. Benè KL, Bergus G. When Learners Become Teachers: A Review of Peer Teaching in Medical Student Education. Fam Med. 2014;46(10):5.

23. Joshi A, Kale S, Chandel S, Pal DK. Likert Scale: Explored and Explained. Curr J Appl Sci Technol. 2015;396-403.

24. Kann L. Youth Risk Behavior Surveillance - United States, 2017. MMWR Surveill Summ.;67.

25. García-Vázquez J, Quintó L, Agulló-Tomás E. Impact of a sex education programme in terms of knowledge, attitudes and sexual behaviour among adolescents in Asturias (Spain). Glob Health Promot. $2019 ; 1757975919873621$.

26. Ketting E, Friele M, Michielsen K, On behalf of the European Expert Group on Sexuality Education. Evaluation of holistic sexuality education: A European expert group consensus agreement. Eur J Contracept Reprod Health Care. 2016;21(1):68-80.

27. Graham A, Moore L, Sharp D, Diamond I. Improving teenagers' knowledge of emergency contraception: cluster randomised controlled trial of a teacher led intervention. BMJ. 2002;324(7347):1179.

28. Mason-Jones AJ, Sinclair D, Mathews C, Kagee A, Hillman A, Lombard C. School-based interventions for preventing HIV, sexually transmitted infections, and pregnancy in adolescents. Cochrane Database Syst Rev. 2016;11:CD006417.

29. Oringanje C, Meremikwu MM, Eko H, Esu E, Meremikwu A, Ehiri JE. Interventions for preventing unintended pregnancies among adolescents. Cochrane Database Syst Rev. 2016;(2).

30. Rahib D, Le Guen M, Lydié N. Baromètre santé 2016. Contraception. Quatre ans après la crise de la pilule, les évolutions se poursuivent. Santé Publique Fr St-Maurice. 2017;

31. Cooper B, Toskin I, Kulier R, Allen T, Hawkes S. Brief sexuality communication-a behavioural intervention to advance sexually transmitted infection/HIV prevention: a systematic review. BJOG Int J Obstet Gynaecol. 2014;121(s5):92-103.

32. Gabarron E, Wynn R. Use of social media for sexual health promotion: a scoping review. Glob Health Action. $2016 ; 9$.

33. Stevens R, Gilliard-Matthews S, Dunaev J, Todhunter-Reid A, Brawner B, Stewart J. Social Media Use and Sexual Risk Reduction Behavior Among Minority Youth: Seeking Safe Sex Information. Nurs Res. 2017;66(5):368-77. 
34. Crocker BCS, Pit SW, Hansen V, John-Leader F, Wright ML. A positive approach to adolescent sexual health promotion: a qualitative evaluation of key stakeholder perceptions of the Australian Positive Adolescent Sexual Health (PASH) Conference. BMC Public Health. 2019;19(1):681.

\section{Tables}

Table 1 - Sample description (at baseline)

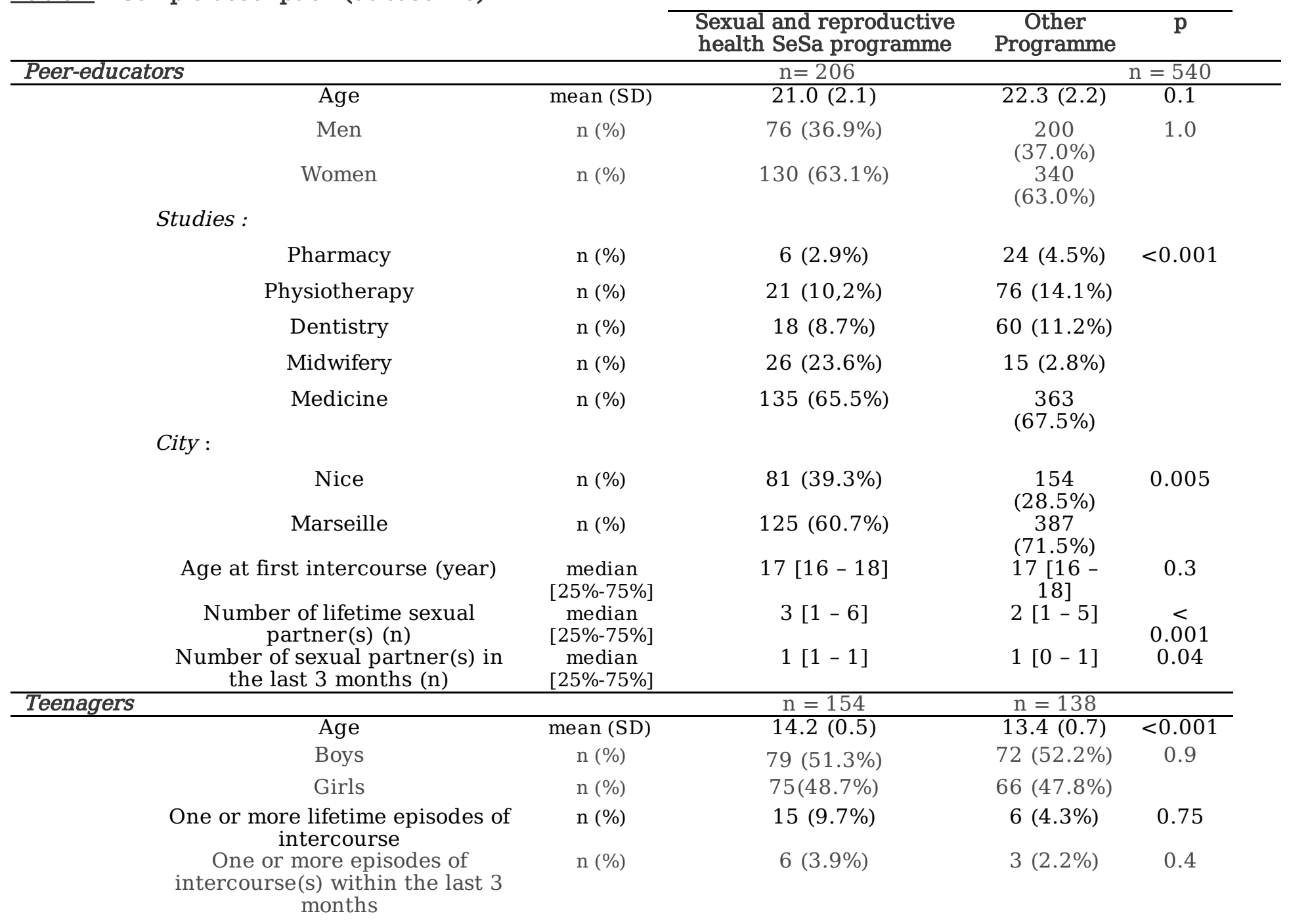

Table 2 - Knowledge and risk perception results 


\begin{tabular}{|c|c|c|c|c|c|c|c|c|c|c|}
\hline & $\begin{array}{l}\text { Before the } \\
\text { programme } \\
\text { mean (SD) }\end{array}$ & $\begin{array}{l}\text { After the } \\
\text { programme } \\
\text { mean (SD) }\end{array}$ & $\begin{array}{l}\text { Difference } \\
\text { (CI 95\%) }\end{array}$ & p & $\begin{array}{c}\text { Before the } \\
\text { programme } \\
\text { mean (SD) }\end{array}$ & $\begin{array}{c}\text { After the } \\
\text { programme } \\
\text { mean (SD) }\end{array}$ & $\begin{array}{l}\text { Difference } \\
\text { (C1 95\%) }\end{array}$ & p & $\begin{array}{l}\text { Detf in deff } \\
\text { (CI 9540) }\end{array}$ & $\begin{array}{l}\text { pbetween } \\
\text { differeaces: }\end{array}$ \\
\hline \multicolumn{11}{|l|}{ Peer-educators } \\
\hline $\begin{array}{c}\text { Score True-False } \\
\text { question } \\
/ 30\end{array}$ & $26.5(2.7)$ & $28.5(2.4)$ & $2.0[1.6-2.5]$ & $<0.001$ & $26.3(3.7)$ & $26.2(4.2)$ & $-0.1[-0.5-0.3]$ & 0.74 & $2.1[1.4-2.9]$ & $<0.001$ \\
\hline Nice & $26.9(2.5)$ & $29.1(1.0)$ & $2.2[1.6-2.8]$ & $<0.001$ & $26.2(3.0)$ & $26.1(5.0)$ & $-0.1[-1.1-0.7]$ & 0.76 & $2.3[0.9-3.7]$ & 0.001 \\
\hline Marseille & $26.2(2.8)$ & $28.3(2.7)$ & $2.1[1.5-2.7]$ & $<0.001$ & $26.3(3.9)$ & 26.2 (3.9) & $=0.1[-0.6-0.5]$ & 0.83 & $2.2[1.2-3.1]$ & $<0.001$ \\
\hline Men & $25.7(2.9)$ & $28.3(2.4)$ & $2.6[1.8-3.4]] \S$ & $<0.001$ & $25.0(4.7)$ & $24.9(5.0)$ & $-0.1[-1.0-0.8]$ & 0.89 & $2.7[1.2-4.3]$ & 0.001 \\
\hline Women & $27.0(2.4)$ & $28.7(2.3)$ & $1.8[1.2-2.3]$ & $<0.001$ & $27.0(2.7)$ & $26.9(3.3)$ & $=0.1[-0.5-0.4]$ & 0.84 & $1.8[1.0-2.6]$ & $<0.001$ \\
\hline $\begin{array}{l}\text { Score Multiple- } \\
\text { Choice Question } \\
\qquad / 30\end{array}$ & $2 p .1(3.3)$ & $21.7(4.0)$ & $1.6[0.9-2.2]$ & $<0.001$ & $19.5(3.5)$ & $18.4(5.0)$ & $-1.1[-1.6--0.7]$ & $<0.001$ & $2.7[1.8-3.6]$ & $<0.001$ \\
\hline Nice & $20.4(3.4)$ & $23.1(2.4)$ & $2.7[1.8-3-6]$ & $<0.001$ & $18.2(4.1)$ & $16.6(6.7)$ & $-1.6[2.8--0.3]$ & 0.01 & $4.3[2.4-6.1]$ & $<0.001$ \\
\hline Marseille & $19.9(3.2)$ & $21.0(4.4)$ & $1.1[0.2-2.0]$ & 0.01 & $20.0(3.1)$ & $18.9(4.2)$ & $-1.1[-1.6--0.6]$ & $<0.001$ & $2.2[1.2-3.2]$ & $<0.001$ \\
\hline Men & $19.5(2.4)$ & $20.5(4.3)$ & $1.0[-0.1-2.1]] \S \S$ & 0.06 & $18.0(4.1)$ & $17.1(5.3)$ & $.0 .9[-1.8-0.0]$ & 0.05 & $3.2[2.1-4.2]$ & $<0.001$ \\
\hline Women & 20.5 (3.6) & $22.4(3.6)$ & $19[1.1-27]$ & $<0.001$ & $20.4(2.7)$ & $19.1(4.7)$ & $-1.3[-1.8--0.7]$ & $<0.001$ & $1.9[0.3-3.5]$ & 0.02 \\
\hline$\underset{15}{\text { Risk perception }}$ & $3.4(0.7)$ & $3.7(0.6)$ & $0.3[0.1-0.4]$ & $<0.001$ & $3.3(0.8)$ & $3.5(0.8)$ & $0.2[0.1-0.3]$ & $<0.001$ & $0.1[0.1-0.3]$ & 0.3 \\
\hline Nice & $3.6(0.7)$ & $3.8(0.6)$ & $0.2[0.0-0.4]$ & 0.05 & $3.3(0.8)$ & $3.5(0.8)$ & $0.2[0.0-0.4]$ & $<0.001$ & $0.0[-0.3-0.3]$ & 0.9 \\
\hline Marseille & $3.3(0.7)$ & $3.6(0.6)$ & $0.3[3.2-3.4]$ & $<0.001$ & $3.3(0.7)$ & $3.5(0.8)$ & $0.2[0.1-0.3]$ & 0.001 & $0.2[-0.4-0.3]$ & 0.1 \\
\hline Men & $3.2(0.7)$ & $3.5(0.7)$ & $0.3[0.1-0.5]$ & 0.002 & $3.0(0.7)$ & $3.3(0.9)$ & $0.3[0.2-0.4]$ & 0.001 & $0.1[-0.2-0.4]$ & 0.6 \\
\hline Women & $3.5(0.7)$ & $3.8(0.6)$ & $0.2[0.1-0.4]$ & 0.002 & $3.5(0.7)$ & $3.6(0.7)$ & $0.1[0.0-0.2]$ & 0.004 & $0.1[-0.1-0.3]$ & 0.3 \\
\hline \multicolumn{11}{|l|}{ Teenagers } \\
\hline $\begin{array}{c}\text { Score True-False } \\
\text { question } / 30\end{array}$ & $13.1(5.9)$ & $19.8(6.8)$ & $6.7[5.2-8.2]$ & $<0.001$ & $11.4(5.6)$ & $12.9(5.9)$ & $1.4[-0.1-2.9]$ & 0.06 & $5.3[3.2-7.4]$ & $<0.001$ \\
\hline Boys & $12.7(5.1)$ & $18.2(7.1)$ & $5.5[3.5-7.5]]$ & $<0.001$ & $11.5(5.3)$ & $12.7(6.9)$ & $1.1[-0.9-3.2]$ & 0.3 & $4.4[1.5-7.2]$ & 0.02 \\
\hline Girls & $13.4(6.8)$ & $21.3(6.1)$ & $7.9[5.7-10.0]] \star$ & $<0.001$ & $11.4(6.0)$ & $13.1(7.4)$ & $1.7[-0.5-4.1]$ & 0.14 & $6.1[3.0-9.3]$ & $<0.001$ \\
\hline $\begin{array}{c}\text { Risk perception } \\
/ 5\end{array}$ & $3.1(0.7)$ & $3.2(0.7)$ & $0.1[-0.6-0.3]$ & 0.21 & $3.0(0.9)$ & $2.9(0.9)$ & $-0.1[-0.3-0.1]$ & 0.30 & $0.2[-0.5-0.5]$ & 0.1 \\
\hline Boys & $3.0(0.7)$ & $3.2(0.7)$ & $0.1[-0.1-0.4]$ & 0.3 & $2.9(0.7)$ & $2.8(0.9)$ & $-0.1[-0.3-0.2]$ & 0.71 & $0.2[-0.2-0.5]$ & 0.4 \\
\hline Girls & $3.11(0.7)$ & $3.2(0.8)$ & $0.1[-0.2-0.3]$ & 0.5 & $3.2(1.0)$ & $3.0(0.9)$ & $-0.2[-0.5-0.1]$ & 0.27 & $0.3[-0.1-0.7]$ & 0.2 \\
\hline
\end{tabular}

* The $\mathrm{p}$ for the interaction between the timing of questionnaire and exposition or not to the SRH SeSa programme.

$\S$ The Difference in differences between women and men: $-0.8[-1.8-0.1] \mathrm{p}=0.07$

$\S \S$ The Difference in differences between women and men: $+0.9[-0.5-2.3] \mathrm{p}=0.2$

$\star$ The differences in scores' change between boys and girls: $+2.3[-0.6-5.2] \mathrm{p}=0.1$

Table 3 - Changes in risky behaviours among healthcare students (= peer educators) SRH peer-educators

Other peer-educators

\begin{tabular}{cccccc}
\hline Before SeSa & After SeSa & $\mathrm{p}$ & Before SeSa & After SeSa & $\mathrm{p}$ \\
\cline { 1 - 1 } \cline { 5 - 6 }$(\mathrm{n})$ & $\%(\mathrm{n})$ & & $\%(\mathrm{n})$ & $\%(\mathrm{n})$ & \\
\cline { 1 - 2 } & 13.2 & 0.61 & 28.5 & 23.1 & 0.43 \\
$(37 / 185)$ & $(30 / 228)$ & & $(128 / 449)$ & $(142 / 616)$ & \\
40.8 & 40.4 & 0.93 & 38.0 & 35.6 & 0.42 \\
$(75 / 184)$ & $(92 / 228)$ & & $(171 / 450)$ & $(219 / 615)$ & \\
12.0 & 14.0 & 0.55 & $13.1(59 / 451)$ & $14.2(87 / 614)$ & 0.61 \\
$(22 / 183)$ & $(32 / 228)$ & & & &
\end{tabular}

* Risky $=$ unprotected sex with an unknown reproductive tract infections status of a partner 
HEALTHCARE STUDENTS

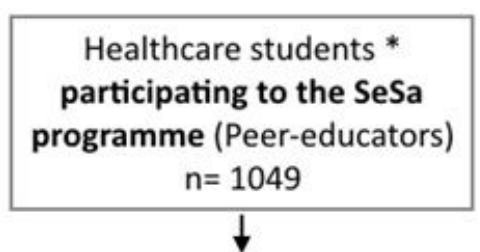

Random allocation to one module of the programme**

$$
\downarrow
$$

Sexual and reproductive

health education

(SRH Peer-Educators)

$$
\mathrm{n}=277
$$

Pre-intervention questionnaire

(response rate)

$\mathrm{n}=\mathbf{2 0 6}(\mathbf{7 4 \% )}$

$$
\downarrow
$$

Addiction / Nutrition /
Dental hygiene (other Peer-
Educators)
$\mathrm{n}=772$

Pré-intervention questionnaire (response rate)

$n=541(70 \%)$

$\downarrow$

\section{Global public health prevention programme}

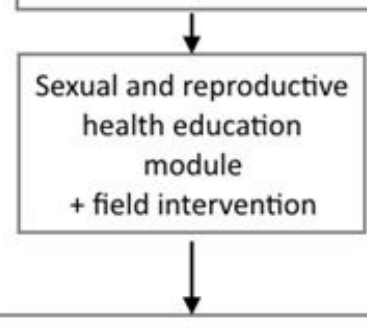

Post-intervention questionnaire (response rate)

$n=254(92 \%)$

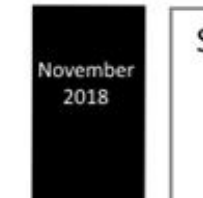

Secondary school students benefiting from the SeSa SHR programme (SeSaIntervention Teenagers)

$\mathrm{n}=225$
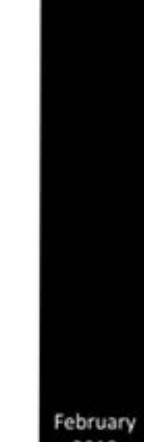

2019

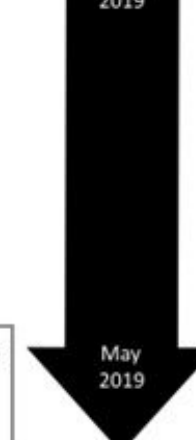

$n=694(90 \%)$
TEENAGERS

Secondary school students benefiting from the classic

french programme (no-

Intervention Teenagers) $\mathrm{n}=176$

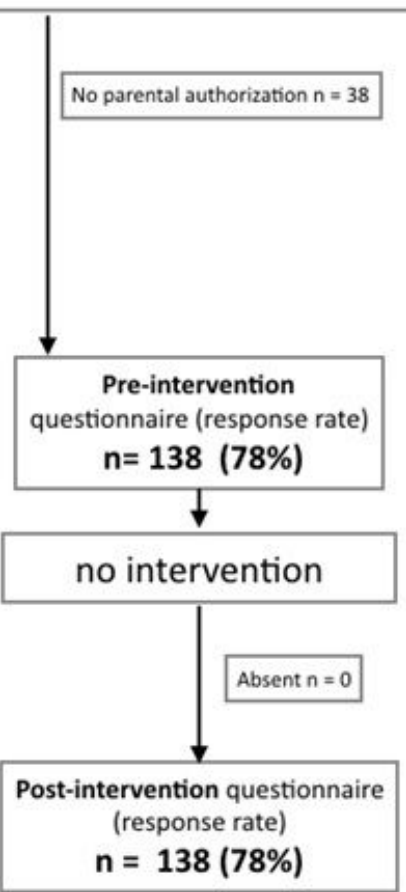

- Third year medical school, 1st year dental school, 1st year midwifery school, 2nd year pharmacy school, 2nd year physiotherapist school * For organizational reasons the Nice's midwives were not randomly assigned

$\mathrm{SeSa}=$ Service Sanitaire (The French Name of public Health prevention national program)

$\mathrm{SRH}=$ Sexual and Reproductive Health

\section{Figure 1}

Study design

\section{Supplementary Files}

This is a list of supplementary files associated with this preprint. Click to download.

- Appendix1.pdf

- Appendix2.pdf

- Appendix3.pdf

- Appendix4.pdf 